\title{
Study for gravel slection and pack operation for oil production well on Song Doc oil field
}

\author{
Quan Anh Tran 1, ${ }^{,}$, An Hai Nguyen ${ }^{1}$, Vinh The Nguyen ${ }^{2}$, Hung Tien Nguyen ${ }^{2}$ \\ ${ }_{1}$ PetroVietnam Exploration and Production Corperation, Hanoi,Vietnam \\ ${ }^{2}$ Hanoi University of Mining and Geology, Hanoi, Vietnam
}

\section{ARTICLE INFO}

Article history:

Received 07th Feb. 2021

Revised $26^{\text {th }}$ May 2021

Accepted $16^{\text {th }}$ June 2021

Keywords:

Gravel packing,

Sand control,

Song Doc oil field.

\section{ABSTRACT}

Sand control by gravel packing is by far the most reliable and effective sand control method and is being used worldwide. One of the most important factor for successful operation is gravel size selection which is suitable with properties of well and particle size of sand from the reservoir, also the operation method needs to be considered during study. Due to the variety of different oilfield, the selections of gravel size and operation method are challenges for petroleum engineer and manager. Oil production wells in Song Doc oil field are producing in Miocene and Oligocene with very high rate of sand production; some of the wells were plugged by sand. Therefore, the study on the selections of gravel size and operation method is needed and important. In this study, theory analyzing was used in order to yield advantage and disadvantage of each gravel packing method and their operation. Based on the operating condition on Song Doc field and the availability of equipment on site, gravel packing method by thru-tubing with vent screen was selected. The coil tubing was chosen as the operation method. This is the best sand control method for the Song Doc oil field with low cost and high effectiveness sand control.

Copyright (C) 2021 Hanoi University of Mining and Geology. All rights reserved.

${ }^{*}$ Corresponding author

E-mail: quanta@pvep.com.vn

DOI: 10.46326/JMES.2021.62(3a).06 


\title{
Tạp chí Khoa học Kỹ thuật Mỏ - Địa chất
}

\section{Nghiên cứu lựa chọn sỏi chèn và phương pháp thi công chèn sỏi nhằm kiểm soát cát trong khai thác dầu khí tại mỏ Sông Đốc}

\author{
Trần Anh Quan ${ }^{1}{ }^{*}$, Nguyễn Hải An ${ }^{1}$, Nguyễn Thế Vinh ${ }^{2}$, Nguyễn Tiến Hung ${ }^{2}$ \\ ${ }^{1}$ Tổng công ty Thăm dò Khai thác dầu khí, Hà Nội, Việt Nam \\ 2 Truờng Đại học Mỏ - Địa chất, Hà Nội, Việt Nam
}

THÔNG TIN BÀI BÁO

\section{TÓM TẮT}

\section{Quá trình:}

Nhận bài 07/02/2021

Sửa xong 26/05/2021

Chấp nhận đăng 16/06/2021

\section{Tùr khóa:}

Chèn sỏi,

Kiểm soát cát,

Mỏ Sông Đốc.
Công nghệ kiểm soát cát sử dụng sỏi chèn là phương pháp đáng tin cậy, hiệu quả và vẫn đang sử dụng rộng rãi trên thế giới. Yếu tố quan trọng quyết định thành công trong phương pháp này là việc lựa chọn kích thước sỏi chèn phù hợp với tính chất hóa lý và kích thước hạt mịn của tầng khai thác cũng như phương pháp thi công phù hợp. Đối với từng điều kiện mỏ khác nhau, việc lựa chọn loại sỏi chèn và phương pháp thi công chèn sỏi gặp nhiều khó khăn và là thách thức lớn đối với các kỹ sư và các nhà quản lý. Các giếng dầu tại mỏ Sông Đốc đang được khai thác trong các địa tầng Mioxen và Oligoxen với hàm lượng cát cao và đã gặp phải tình trạng tắc nghẽn do cát xâm nhập. Vì vậy việc nghiên cúu lựa chọn loại sỏi chèn và phương pháp thi công tại thời điểm này là cấp thiết và thời sự. Trong nghiên cúu này, nhóm tác giả sử dụng phương pháp phân tích lý thuyếtcác phương pháp chèn sỏi nhằm đưa ra ưu và nhược điểm của công nghệ chèn sỏi cũng như phưong pháp thi công tương úng chúng. Dựa trên điều kiênn thực tể và đặc thù của các giếng khai thác dầu cũng như trang thiết bị sẵn có tại mỏ Sông Đốc, nhóm tác giả nhận thấy, phương pháp thi công chèn sỏi sử dụng cáp tời với công nghề vent screen là phù hợp nhất dựa trên việc sử dụng phần mềm chạy mô phỏng giếng khai thác với các phương pháp khác nhau. Phương pháp được nhóm tác giả đề xuất đảm bảo kiểm soát cát tốt nhất với chi phí thấp nhất.

(C) 2021 Trường Đại học Mỏ - Địa chất. Tất cả các quyền được bảo đảm.

\section{Mở đầu}

Mỏ Sông Đốc nằm ngoài khơi thềm lục địa Việt Nam, phía Bắc của khu vực khai thác chung

\section{${ }^{*}$ Tác giả liên hê}

E-mail: quanta@pvep.com.vn

DOI: 10.46326/JMES.2021.62(3a).06
PM - 3 CAA, cách mũi Cà Mau 205 km về phía nam và cách mỏ Bunga Kekwa 15 km về hướng tây - bắc. Hiện tại, mỏ Sông Đốc có 11 giếng đang khai thác dầu trong các địa tầng Mioxen và Oligoxen với đá chứa là các tập cát kết. Chất lưu khai thác tại đây có hàm lượng cát cao và gặp phải tình trạng tắc nghẽn do cát xâm nhập. Việc lựa chọn phương pháp kiểm soát cát cho các 
giếng tại mỏ Sông Đốc là nhiệm vụ cấp bách trong điều kiện mỏ đang suy giảm sản lượng và hàm lượng cát trong quá trình khai thác càng lớn.

Nhiều phương pháp kiểm soát cát đã được nghiên cứu và ứng dụng cho các mỏ dầu khí trên thế giới với những ưu, nhược điểm và phạm vi ứng dụng khác nhau (Carlson và nnk., 1992; Glenn và nnk., 1975). Chèn sỏi là một phương pháp kiểm soát cát được xem là hiệu quả, đáng tin cậy nhất và đang được sử dụng rộng rãi cho đến nay (Saebi và nnk., 2010). Trước đây, thi công chèn sỏi với phương pháp truyền thống yêu cầu sử dụng giàn khoan, thường áp dụng cho các giếng mới hoặc giếng sửa chữa, không thích hợp cho các giếng đang khai thác cần sửa chữa với chi phí thấp. Ngày nay, với công nghệ ngày càng phát triển, việc thi công chèn sỏi trong ống chống được ứng dụng rộng rãi và đã khắc phục được các nhược điểm trên (Saebi và nnk., 2010). Tuy nhiên, đối với điều kiện đặc thù của các mỏ khác nhau phương pháp này vẫn đối mặt với nhiều thách thức nhất định (Trần Anh Quân và nnk., 2020). Trong nghiên cứu này, các tác giả đã khái quát các công nghệ thi công chèn sỏi hiện đang được sử dụng trên thế giới, đánh giá ưu, nhược điểm và phạm vi ứng dụng của từng phương pháp. Sau đó, tiến hành lựa chọn phương pháp thi công phù hợp với lợi ích kinh tế, điều kiện thiết bị và cơ sở hạ tầng của mỏ Sông Đốc.

\section{Các phương pháp thi công chèn sỏi}

\subsection{Phương pháp thi công chèn sỏi truyền thống}

Phương pháp này chính là việc đưa các hạt sỏi chèn có kích thước được lựa chọn phù hợp với tính chất hóa lý và kích thước hạt mịn của tầng khai thác. Các hạt sỏi chèn này được đưa xuống đáy giếng thông qua dung dịch và đi vào trong khoảng không vành xuyến tạo thành một lớp lọc giữa vỉa và đáy giếng. Bên cạnh đó, lớp sỏi chèn này đồng thời cũng gia cố thành hệ, hạn chế các hạt mịn bở rời sinh ra từ thành hệ xâm nhập vào trong giếng.

Việc tính toán kích thước sỏi chèn phù hợp giúp cho độ thấm của lớp sỏi cao hơn so với các phương pháp khác và cho hệ số khai thác của giếng tốt hơn. Phương pháp chèn sỏi truyền thống có chi phí thi công lắp đặt ban đầu lớn so với các phương pháp khác (ống lọc, ống lọc bọc sỏi (chèn sẵn) hay gia cố tầng khai thác,...) (Heriot Watts University, 2011), tuy nhiên quá trình vận hành sẽ cho hiệu quả cao hơn do chi phí vận hành thấp, ít phải sửa chữa đồng thời cải thiện được lưu lượng khai thác. Bên cạnh đó, phương pháp chèn sỏi còn tồn tại nhiều nhược điểm, có thể kể ra như: quá trình thi công phức tạp, phụ thuộc nhiều vào cấu trúc giếng khoan; hoàn thiện giếng bằng phương pháp này khiến cho quá trình sửa chữa giếng khoan sau này trở nên khó khăn, phức tạp, giảm tính linh hoạt so với các phương pháp khác. Đặc biệt, với các giếng khoan ngang, khoan xiên, việc bơm dung dịch chứa sỏi chèn vào khoảng không vành xuyến giữa thành hệ và ống chống (lưới lọc) là phức tạp và khó đảm bảo mức độ đồng đều của lớp sỏi chèn.

Các phương pháp chèn sỏi truyền thống được sử dụng phổ biến trong công nghiệp dầu khí hiện nay là chèn sỏi trong và chèn sỏi ngoài. Phương pháp chèn sỏi ngoài thường sử dụng cho các giếng hoàn thiện thân trần, chèn sỏi trong thường áp dụng cho các giếng được chống ống và mở vỉa tại tầng sản phẩm.

Phương pháp chèn sỏi ngoài (Hình 1) áp dụng cho các giếng hoàn thiện thân trần, không chống ống tại tầng khai thác. Sỏi chèn được bơm xuống trong khoảng không vành xuyến giữa ống khai thác và thành hệ. Trong một số trường hợp, sử dụng thêm lưới lọc hay ống lọc đục lỗ sẵn trong bộ hoàn thiện, sau đó sỏi được bơm chèn vào giữa thành hệ và lưới lọc nhằm gia tăng khả năng kiểm soát cát. Trong trường hợp này, ứng suất đất đá của tầng vỉa sản phẩm phải đủ lớn để chịu được lực tác động của lớp sỏi chèn. Để thi công chèn sỏi ngoài, cần phải tiến hành khoan mở rộng thành giếng khoan tại khu vực hoàn thiện giếng với mục đích tăng tiết diện đáy giếng, đảm bảo lớp sỏi chèn đủ dày để tăng cường khả năng kiểm soát cát.

Nhìn chung, việc thi công chèn sỏi ngoài yêu cầu sử dụng giàn khoan, thường áp dụng trong trường hợp hoàn thiện giếng mới, không thích hợp cho các giếng đang khai thác, cần sửa chữa với chi phí thấp nên khó áp dụng cho các mỏ nhỏ, cận biên, thời gian khai thác còn lại ngắn.

Đối với phương pháp chèn sỏi trong, sỏi được đưa xuống đáy giếng và lấp đầy khoảng không vành xuyến giữa ống khai thác (hoặc lưới lọc) và ống chống, và đi sâu vào các lỗ bắn mở vỉa (Hình 2). Do sỏi được chèn bên trong ống chống 


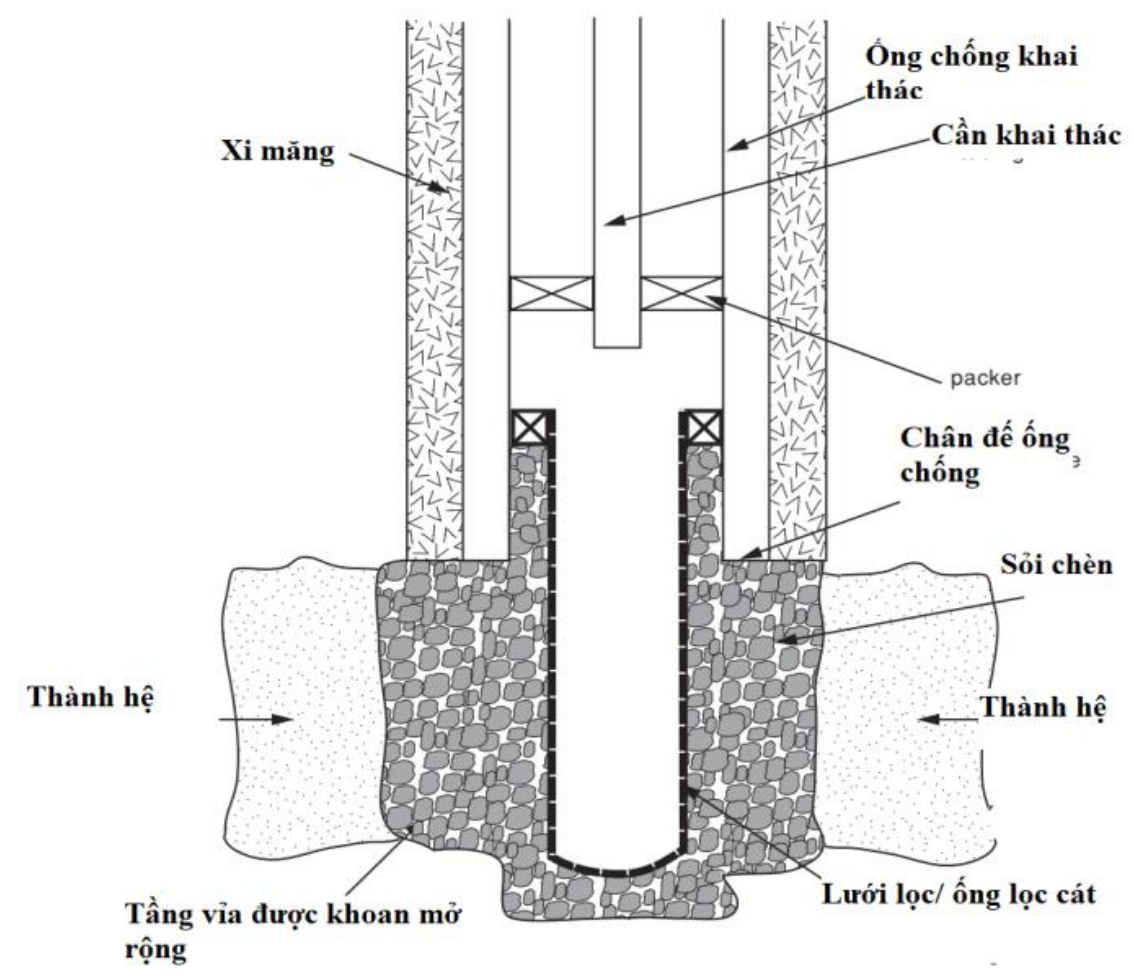

Hình 1. Phương pháp chèn sỏi ngoài.

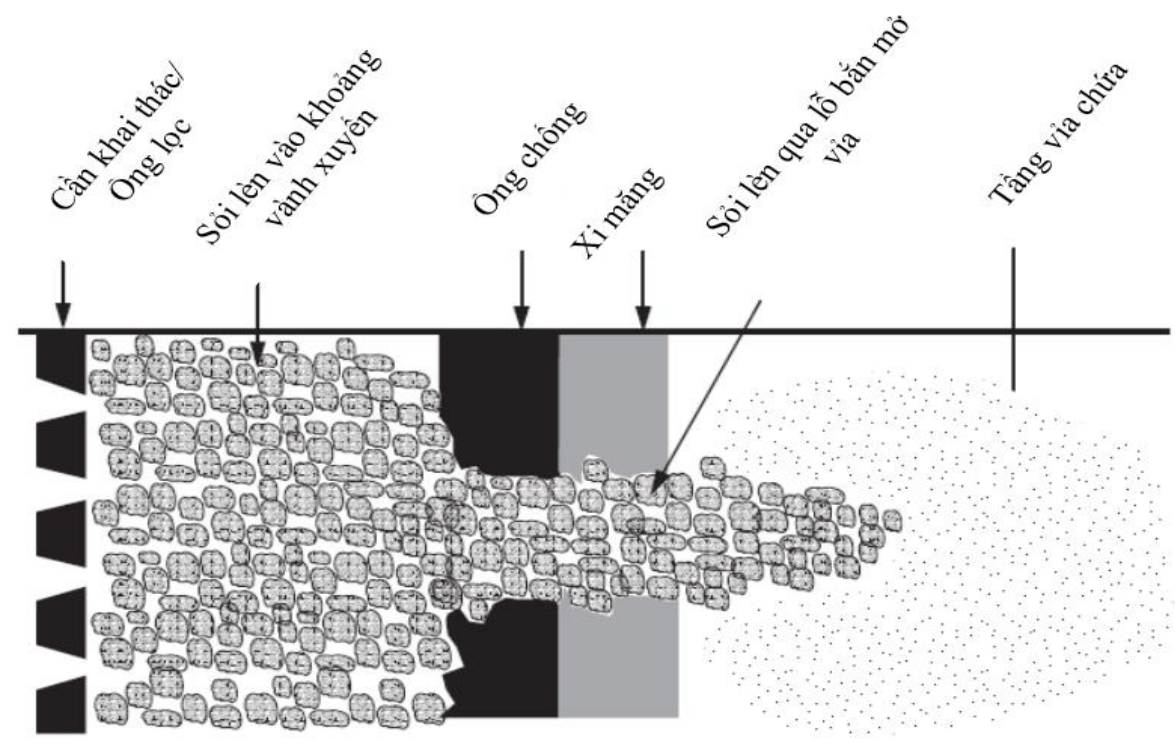

Hình 2. Phương pháp chèn sỏi trong.

nên được gọi là chèn sỏi trong.

Trên thực tế, rất khó đạt được hiệu quả cao trong thi công chèn sỏi, đặc biệt đối với các vỉa mỏng chứa các tập cát kết xen kẹp bởi các tập sét. Với sự phát triển của công nghệ hiện nay, hoàn thiện giếng sử dụng ống chống, bắn mở vỉa và làm sạch vùng đáy giếng ngày càng được hoàn thiện, làm cho việc sử dụng công nghệ chèn sỏi trong càng trở nên phổ biến và được áp dụng rộng rãi trong ngành công nghiệp dầu khí. Một lợi thế khác của phương pháp chèn sỏi trong là việc lựa chọn khoảng bắn mở vỉa ngày càng dễ dàng và linh hoạt, công tác bơm sỏi chèn vào khoảng không vành xuyến trở nên thuận lợi hơn (Heriot Watts University, 2011). 


\subsection{Phương pháp chèn sỏi trong sử dụng ống cuộn mềm (coil - tubing)}

Phương pháp chèn sỏi sử dụng ống cuộn mềm (Hình 3) giới thiệu lần đầu năm 1970 (Shurtz và nnk., 1975) và được xem là phương pháp hiệu quả cho việc sửa chữa các giếng khai thác dầu khí bị tắc nghẽn do cát xâm nhập.

Trong thời gian đầu, phương pháp thi công này không cho phép sỏi chèn được bơm tuần hoàn, đến những năm 90 của thế kỉ trước với sự phát triển của công nghệ thi công cáp tời đã cho phép sỏi chèn được bơm tuần hoàn trong lòng giếng và rất phù hợp cho việc thi công cho các giếng có đường kính ống khai thác nhỏ (Bell và nnk., 2001).

Ngoài ra, việc sử dụng phương pháp thi công bằng ống cuộn mềm có thể tận dụng được ưu điểm của phương pháp chèn sỏi truyền thống nhưng lại không cần phải huy động giàn khoan, qua đó tiết kiệm được chi phí thuê giàn khoan. Đồng thời, với đặc thù cho các mỏ ở Việt Nam, việc sử dụng ống cuộn mềm sẽ giảm việc phụ thuộc vào cửa sổ thời tiết so với việc huy động giàn khoan.

Với các ưu điểm trên, phương pháp chèn sỏi trong kết hợp lưới lọc thường được xem xét áp dụng cho các mỏ/ giếng có trữ lượng thu hồi thấp, sửa chữa các giếng giảm sản lượng do cát bít nhét.

\subsection{Lựa chọn sỏi chèn}

Lớp sỏi chèn đóng vai trò là tấm phin lọc ngăn ngừa cát xâm nhập vào giếng, gia cố thành hệ tầng vỉa sản phẩm, đồng thời phải đảm bảo độ thấm đủ tốt để hạn chế cản trở dòng chất lưu từ vỉa vào đáy giếng. Các hạt sỏi chèn có kích thước được lựa chọn phù hợp với tính chất hóa lý và kích thước hạt mịn của tầng khai thác. Việc tính toán kích thước các hạt sỏi chèn cũng giúp cho độ thấm của lớp sỏi này cao hơn so với các phương pháp khác nên sẽ cho hệ số khai thác của giếng tốt hơn (Saucier, 1974).

Việc nghiên cứu và lựa chọn kích cỡ sỏi chèn là một thách thức của phương pháp thi công chèn sỏi. Nếu kích cỡ sỏi chèn lựa chọn phù hợp với kích thước của hạt mịn (cát) thì lớp sỏi chèn này sẽ đóng vai trò như một lớp đá chứa có độ thấm cao, đồng thời các lỗ rỗng của lớp này vừa đủ để ngăn ngừa cát xâm nhập vào giếng (Heriot Watts University, 2011).

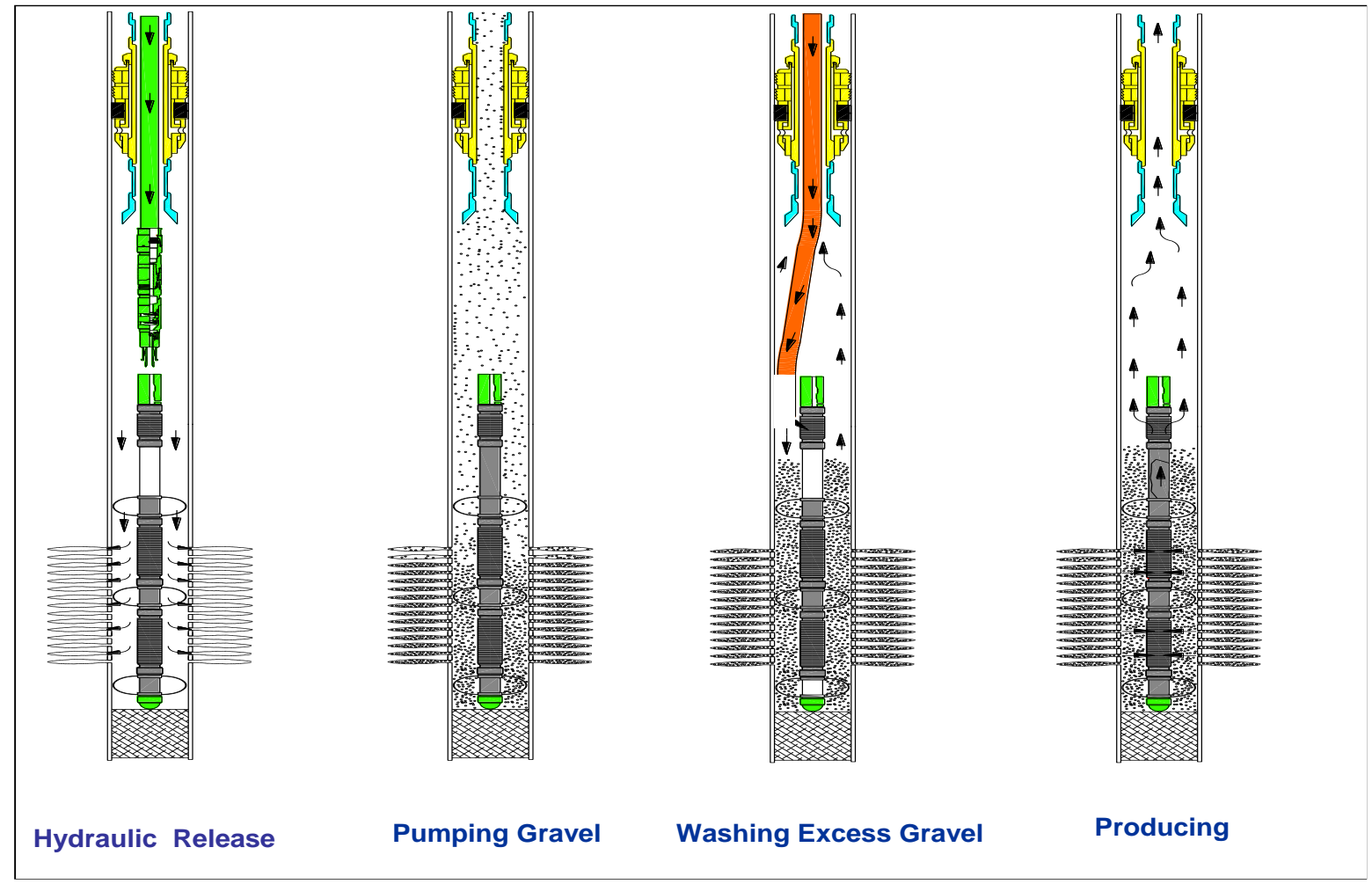

Hình 3. Thi công chèn sỏi trong bằng ống cuộn mềm tại giếng NH - 1P. (a: thả lưới lọc bằng ống cuộn mềm; b: bơm sỏi chèn; c: tuần hoàn làm sạch sau khi bơm sỏi; $d$ : đưa giếng vào khai thác) 
Ngược lại, nếu lựa chọn kích cỡ sỏi chèn không phù hợp sẽ không có tác dụng ngăn ngừa cát hoặc tạo ra lớp sỏi chèn có độ thấm quá thấp, cản trở chất lưu chảy từ vỉa vào đáy giếng. Với sỏi chèn có kích thước quá lớn so với kích thước hạt cát, kích thước lỗ rỗng giữa các hạt chèn không đủ nhỏ để ngăn chặn được các hạt mịn (Hình 4a). Sỏi chèn có kích thước quá nhỏ dẫn đến lỗ rỗng giữa các hạt không đủ lớn và có thể bị bít nhét bởi các hạt cát sinh ra từ thành hệ, làm giảm độ thấm của lớp sỏi chèn và năng suất khai thác (Hình 4b).

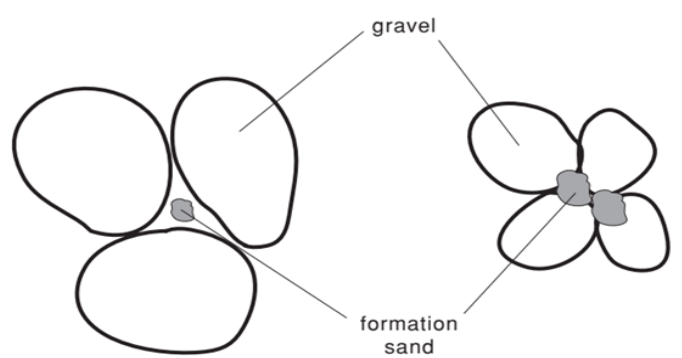

(a)

(b)

Hình 4. Ảnh hưởng của kích cỡ hạt chèn tới việc kiểm soát cát của phưong pháp chèn sỏi: (a) hạt chèn kích thước quá to; (b) hạt chèn kích thước quá nhỏ.
Việc lựa chọn kích cỡ sỏi chèn phụ thuộc nhiều vào kết quả phân tích mẫu hạt mịn sinh ra từ thành hệ. Do đó, cần tiến hành phân tích mẫu lõi và thực hiện thí nghiệm nhằm đưa ra đường cong phân bố hạt cũng như hệ số đồng nhất của đất đá $(\mathrm{C})$. Đã có nhiều nghiên cứu được thực hiện để đưa ra các tiêu chuẩn chung trong việc lựa chọn sỏi chèn, điển hình trong đó phải kể đến nghiên cứu của Saucier (1974). Theo nghiên cứu này, Saucier đã đưa ra được tiêu chí lựa chọn sỏi chèn có kích thước từ $3 \div 6$ lần kích thước hạt mịn nhằm đạt được độ thấm tối ưu và hạn chế tối đa khả năng sinh cát cho giếng (Hình 5).

\section{Lựa chọn công nghệ kiểm soát cát phù hợp với điều kiện mỏ Sông Đốc}

Hiện tại, sản lượng khai thác của mỏ Sông Đốc đang suy giảm nhanh, phần lớn các giếng trong tình trạng ngập nước trên $80 \%$. Các vỉa đang khai thác thuộc địa tầng Mioxen và Oligoxen với đất đá chủ yếu là cát kết đồng bằng ven biển, sét kết và lớp than mỏng xen kẹp. Các tập cát kết tại đây có độ dày từ $5 \div 25 \mathrm{~m}$ với độ rồng trung bình khoảng $22 \div 26 \%$, có đặc tính bở rời và mức độ gắn kết yếu (Trần Anh Quân và nnk, 2020).

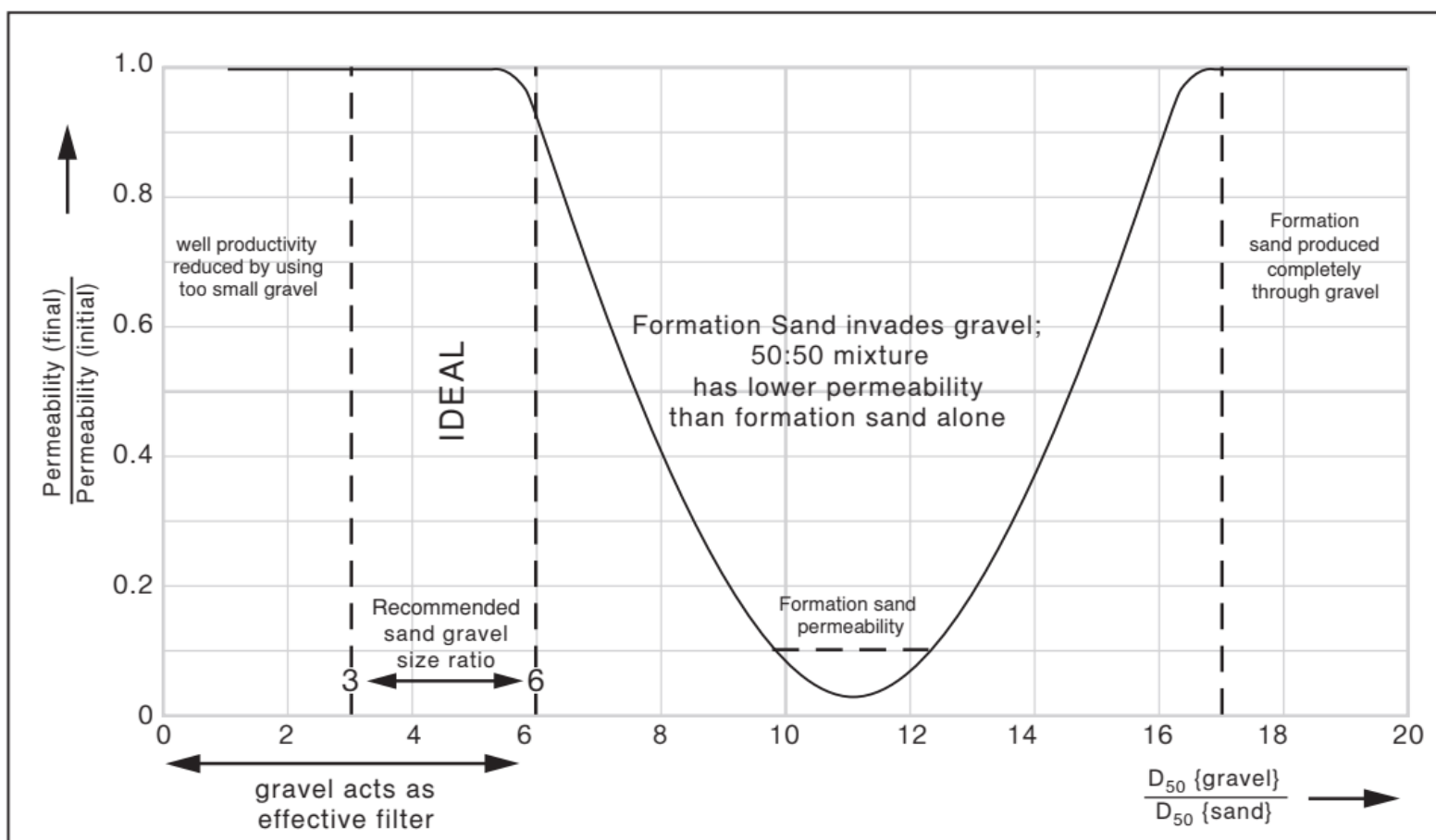

Hình 5. Độ thấm ảnh hưởng bởi kích thước sỏi chèn so với kích thước hạn mịn (Saucier và nnk., 1974). 
Do đó, cần nghiên cứu lựa chọn phương pháp kiểm soát cát phù hợp với điều kiện của mỏ. Việc lựa chọn này cần đảm bảo: kiểm soát tốt tình trạng cát xâm nhập; không làm giảm lưu lượng khai thác; chi phí thấp.

Để tiến hành nghiên cứu lựa chọn phương pháp kiểm soát cát cho mỏ Sông Đốc, nghiên cứu này đã chọn giếng Ngọc Hiển - $1 \mathrm{P}(\mathrm{NH}-1 \mathrm{P})$ làm đối tượng nghiên cứu, do có những đặc điểm đặc trưng cho các giếng tại mỏ như: tầng vỉa sản phẩm chủ yếu là các tập cát kết có tính liên kết kém; không có thiết kế kiểm soát cát ban đầu; trong quá trình khai thác bị cát xâm nhập và dẫn đến tắc nghẽn.

Với trữ lượng còn lại của mỏ, việc điều động giàn khoan để tiến hành thi công kiểm soát cát bằng phương pháp truyền thống sẽ không đạt hiệu quả kinh tế như phân tích bên trên. Do đó, nghiên cứu đề xuất ứng dụng phương án thi công kiểm soát cát không sử dụng giàn khoan cho giếng $\mathrm{NH}$ - 1P. Các phương án kiểm soát cát không sử dụng giàn khoan có thể kể đến: gia cố tầng vỉa sản phẩm bằng hóa chất; sử dụng hạt chèn để gia cố tầng sản phẩm; phương pháp chèn sỏi trong sử dụng ống cuộn mềm.

Các phương pháp sử dụng hóa chất hay hạt chèn để gia cố tầng sản phẩm không hiệu quả đối với đặc điểm của giếng $\mathrm{NH}-1 \mathrm{P}$ do chiều dài vỉa tại đây lớn và có thể làm nhiễm bẩn thành hệ bởi các loại hoá phẩm (Heriot Watts University, 2011). Việc thi công lắp đặt lưới lọc không sỏi chèn có thể thi công bằng phương pháp cáp tời, tuy nhiên đây không phải là phương pháp tối ưu do các hạt cát có thể bít nhét các lỗ bắn mở vỉa và khoảng không vành xuyến quanh lưới lọc.

Sau khi xem xét, đánh giá đặc tính vỉa chứa cũng như ưu nhược điểm của các phương pháp thi công không sử dụng giàn khoan, nhóm tác giả nhận thấy phương pháp thi công chèn sỏi trong bằng ống cuộn mềm là phương pháp phù hợp và tối ưu nhất để kiểm soát cát cho giếng NH - 1P.

\section{Phương án thi công và lựa chọn sỏi chèn cho giếng NH - 1P}

Để triển khai thi công chèn sỏi trong nhằm kiểm soát cát, kích thước hạt sỏi chèn cần phải được lựa chọn cho phù hợp. Nhằm xác định kích thước sỏi chèn, nhóm nghiên cứu tiến hành phân tích mẫu hạt mịn sinh ra từ thành hệ để đưa ra đường cong phân bố hạt. Kết quả phân tích cho thấy, hệ số đồng nhất của đất đá (C) đối với mẫu hạt mịn của giếng $\mathrm{NH}-1 \mathrm{P}$ là $\mathrm{C}=2,7$ và kích thước trung bình hạt mịn là $247 \mu \mathrm{m}$ (Hình 6). Dựa theo nghiên cứu của Saucier (1974), loại sỏi chèn phù hợp với đặc tính hạt mịn của giếng NH - 1P 12/20 (theo tiêu chuẩn Mỹ). Loại lưới lọc được sử dụng để kết hợp với sỏi chèn là loại lưới 1,66 inch được chế tạo bởi công ty Baker Hughes. Đây là loại lưới được sản xuất công nghiệp với kích thước mắt lưới là $10 \mathrm{~mm}$ phù hợp với sỏi chèn cỡ 12/20 (tiêu chuẩn Mỹ).

Một yếu tố quan trọng quyết định thành công trong việc thi công chèn sỏi bằng ống cuộn mềm chính là việc đảm bảo các lỗ bắn mở vỉa được lấp đầy các hạt sỏi chèn thay vì bị bít nhét bởi cát sinh ra từ thành hệ. Vì lý do này, việc bắn mở vỉa bổ sung dưới áp suất cân bằng (under balance perforation) trước khi thi công chèn sỏi là cần thiết để đảm bảo các lỗ bắn mở vỉa không bị bít nhét bởi cát từ thành hệ. Mật độ và đường kính của các lỗ bắn mở vỉa phải đủ lớn để đảm bảo các lỗ này được đều được chèn đầy sỏi. Ngoài ra, các lỗ bắn mở vỉa có mật độ cao và đường kính lớn đảm bảo giảm thiểu tổn hao áp suất của dòng chảy khi đi qua chúng và vận tốc dòng chảy của chất lưu từ vỉa vào đáy giếng giúp giảm sự mài mòn và tăng tuổi thọ lớp lưới lọc phía trong. Nhóm tác giả sử dụng phần mềm mô phỏng trên máy tính (WellFlo) nhằm đánh giá kết quả kiểm soát cát đối với phương pháp chèn sỏi trong bằng ống cuộn mềm. Thông qua phần mềm mô phỏng, nhận thấy việc bắn mở vỉa lại giúp tăng mật độ, khơi thông các lỗ bắn cũ và tăng sản lượng khai thác của giếng. Ngoài ra, các phương án hoàn thiện giếng cũng được đưa vào phần mềm mô phỏng nhằm đánh giá hiệu quả của chúng. Từ đó, lựa chọn được phương án thi công cho kết quả tốt nhất. Các thông số sau được đưa vào phần mềm mô phỏng nhằm đánh giá độ nhạy của sản lượng khai thác giếng tương ứng với từng thông số sau khi xử lý kiểm soát cát bằng sỏi chèn: loại đạn bắn mở vỉa: đạn xuyên phá (DP) và đạn nổ (GP); loại sỏi chèn theo tiêu chuẩn Mỹ: $30 / 50$; 20/40; 12/20.

Quy trình thi công lắp đặt bộ hoàn thiện giếng sử dụng phương pháp chèn sỏi trong bằng ống cuộn mềm được thể hiện trong Hình 3.

Theo tính toán tốc độ bơm sỏi chèn $5 \mathrm{ft} / \mathrm{s}$ và mật độ sỏi chèn dao động trong khoảng $0,5 \div 1,0$ ppg là tối ưu đối với điều kiện giếng NH - 1 P. 


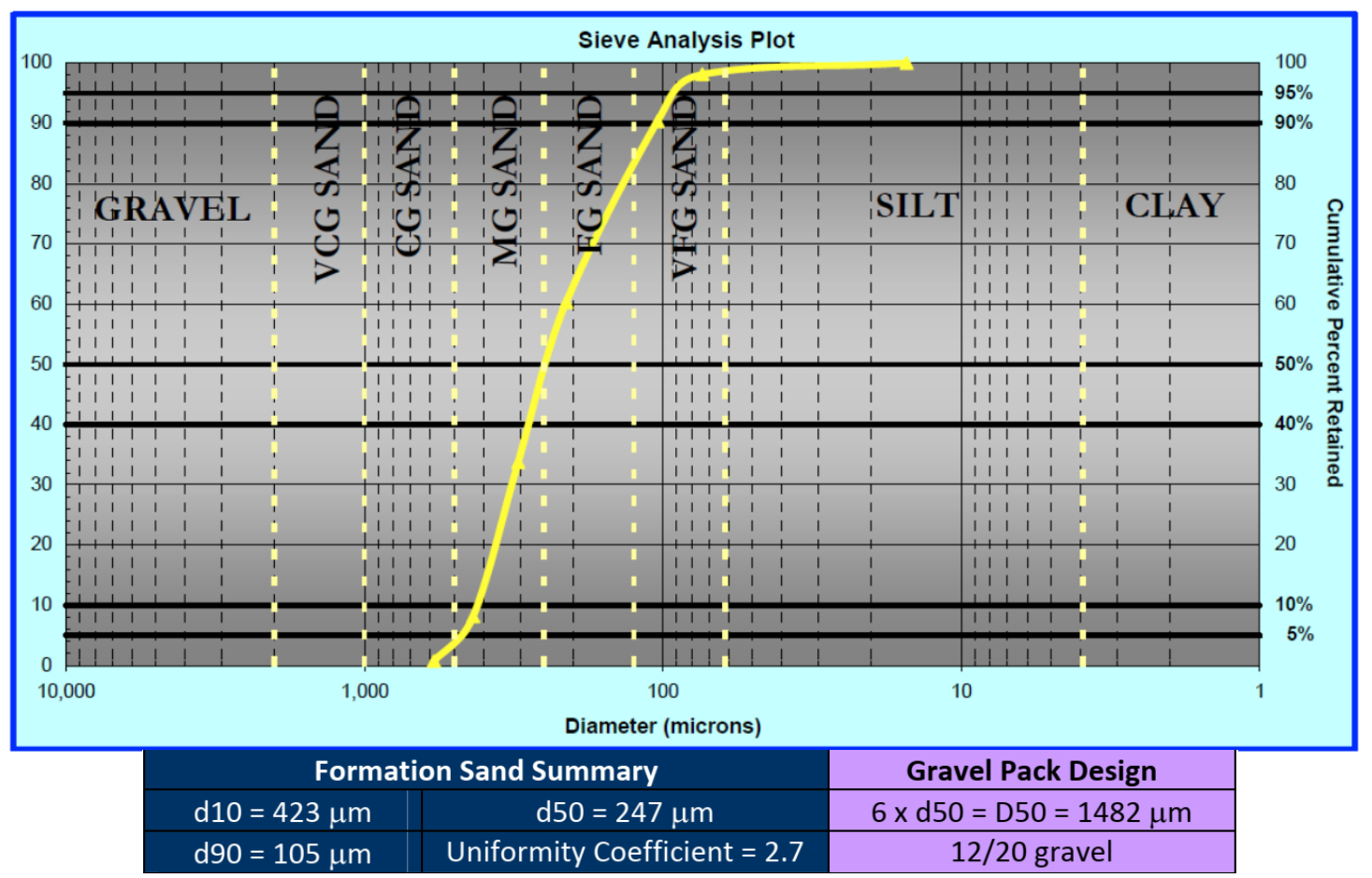

Hình 6. Đường cong phân bố kích thước hạt và hệ số đồng nhất hạt cát từ giếng NH - 1P.

Việc thi công lắp đặt lưới lọc và chèn sỏi bằng ống cuộn mềm có thể gặp các rủi ro: cát còn tồn đọng trong giếng do chưa được làm sạch triệt để trước khi thi công; việc làm kín packer không được triệt để dẫn đến phải tiến hành làm kín lại; phun trào mất kiểm soát nên trong quá trình thi công cần chuẩn bị dung dịch kiểm soát giếng để sử dụng khi cần thiết.

\section{Kết luận}

Từ những nghiên cứu bên trên, có thể đưa ra một số kết luận sau:

- Mỏ Sông Đốc là mỏ nhỏ, cận biên, vì vậy để kiểm soát cát, phương pháp chèn sỏi trong bằng ống cuộn mềm sử dụng 2 lưới lọc "vent - screen" là phù hợp với lợi ích kinh tế và điều kiện thiết bị sẵn có của mỏ;

- Trong công tác thi công chèn sỏi tại mỏ cần tiến hành bắn mở vỉa lại dùng loại đạn nổ (Gravel pack charge) với mật độ 6 lỗ/feet và;

- Sỏi chèn thương mại loại 12/20 là phù hợp giúp kiểm soát cát hiệu quả mà vẫn đảm bảo được độ thấm tốt của lớp sỏi chèn;

- Tốc độ bơm sỏi chèn $5 \mathrm{ft} / \mathrm{s}$ và mật độ sỏi chèn dao động trong khoảng $0,5 \div 1,0$ ppg là tối ưu đối với điều kiện giếng tại mỏ Sông Đốc;
- Cần nghiên cứu và dự báo trước các rủi ro trong thi công chèn sỏi trong bằng ống cuộn mềm để kịp thời đưa ra phương án khắc phục khi cần thiết;

\section{Đóng góp của các tác giả}

Tác giả Trần Anh Quân lên kế hoạch, tiến hành thu thập, xử lý số liệu và kiểm tra tiến độ công việc. Nguyễn Thế Vinh và Nguyễn Tiến Hùng tiến hành phân tích lý thuyết các phương pháp kiểm soát cát trong khai thác dầu khí. Nguyễn Hải An thu thập số liệu và chỉnh sửa một số nội dung.

\section{Tài liệu tham khảo}

Bell Jr. PE. T. A., Martch Jr. W. E. and Morrison. D. W. (2001). Achieving High Rate Completions with Innovative Thru Tubing Sand Control.SPE 68935, 56- 62.

Carlson J, Gurley D, King G, Price - Smith C and Waters F. (1992). Sand control: Why and How?. Oilfield Review, 4(4), 41 - 53.

Glenn C, Shurtz, Bob G, Comeaux. (1975). New Through - Tubing Gravel Pack Techniques. SPE - 5660, 92 - 98. 
Heriot Watts University. (2011). Production technology. Petroleum Institue, chapter 10, 826 pages.

Saucier R. J. (1974). Considerations in gravel pack design. SPE 4030, Journal of Petroleum Technology, 205 - 212.

Saebi S., Afendy M. N., Munoz I., Roslan M. R., Nazar M., Deris M. and Mohamad M. H. (2010). Rigless through - tubing gravel pack for sand control in Malaysia. World Oil, 95 102.

Trần Anh Quân, Nguyễn Hải An, Nguyễn Thế Vinh, Nguyễn Tiến Hung. (2020). Giải pháp tối ưu thiết bị lòng giếng nhằm ngăn ngừa và kiem soát cát giếng Ngọc Hiền - 1p mỏ Song Đốc, bể Malay - Thổ Chu. Hội nghị toàn quốc về Khoa học Trái đất và Tài nguyên với phát triển bền vũ̃ng. Trường Đại học Mỏ Địa chất, 48 - 56. . 